\title{
Morphological Analysis of Co-evaporated Blend Films Based on Initial Growth for Organic Photovoltaics
}

\author{
Yosei Shibata $^{\mathrm{a}^{*}}$, Tetsuya Taima ${ }^{\mathrm{a}, \mathrm{b}}$, Ying Zhou ${ }^{\mathrm{a}}$, Noboru Ohashi ${ }^{\mathrm{a}}$, \\ Takahiro Kono $^{\text {a }}$, and Yuji Yoshida ${ }^{a^{*}}$ \\ a Research Center for Photovoltaic Technologies, National Institute of Advanced \\ Industrial Science and Technology, 1-1-1 Higashi, Tsukuba, Ibaraki, 305-8565, Japan \\ b Japan Science and Technology Agency, PRESTO, 4-1-8 Honcho, Kawaguchi, Saitama, \\ 332-0012, Japan
}

Journal: Applied Surface Science

KEYWORDS: co-evaporation, initial growth, bulk heterojunction, blend morphology, organic photovoltaics

*Corresponding Authors

Research Center for Photovoltaic Technologies, National Institute of Advanced Industrial Science and

Technology, Central 5, 1-1-1 Higashi, Tsukuba, Ibaraki 305-8565, Japan

Zip-code: 305-8565

1) Dr. Yosei Shibata E-mail: yosei.shibata@aist.go.jp

Phone: +81-29-861-8780 Fax:+81-29-861-6232

2) Dr. Yuji Yoshida E-mail: yuji.yoshida@aist.go.jp

Phone: +81-29-861-9423 Fax: +81-29-861-6232 


\begin{abstract}
Bulk heterojunction structures composed of electron donor and acceptor molecules for application in high-performance organic photovoltaics studied. To fabricate these structures, the co-evaporation method in vacuum is commonly applied; however, the details of the crystal growth process during co-evaporation have not yet been established.
\end{abstract}

Here, we focused on structural analysis of blend films composed of phthalocyanine and fullerene based on initial growth stage. Similar crystal growth behavior to that typically observed in single-component molecules is obtained for the films. These results suggest that the competitive crystal growth between donors and acceptors occurs during co-evaporation process. The balance of thin film growth among donor and acceptor molecules can be related to improved photovoltaic performance. The homogeneous blend structure leads to improvement of the power conversion efficiency from $1.2 \%$ to $3.0 \%$. 


\section{Graphical Abstract}

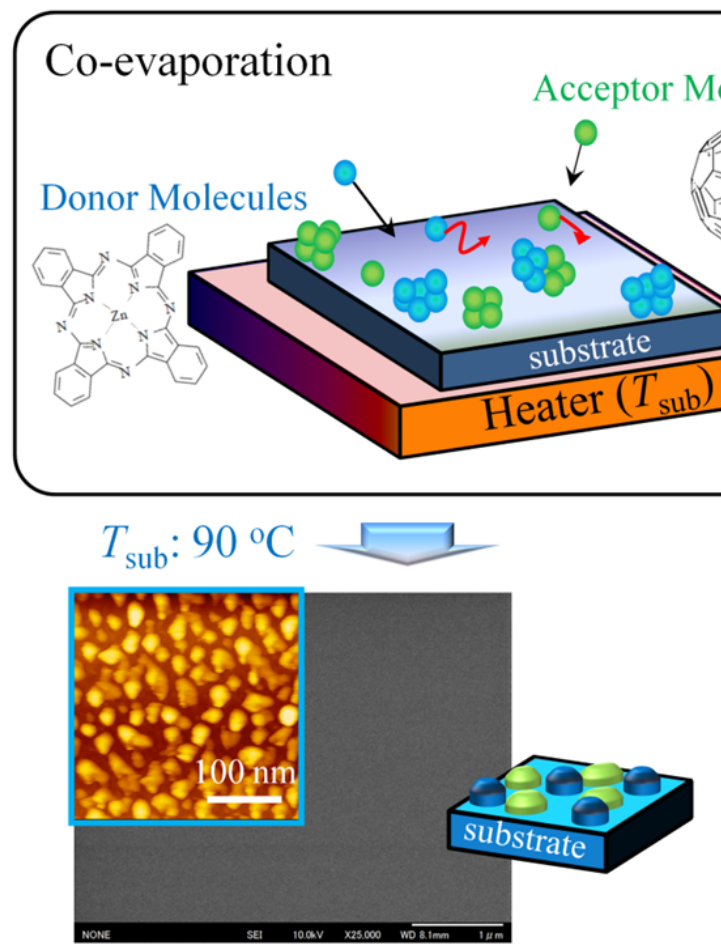

Balanced Growth
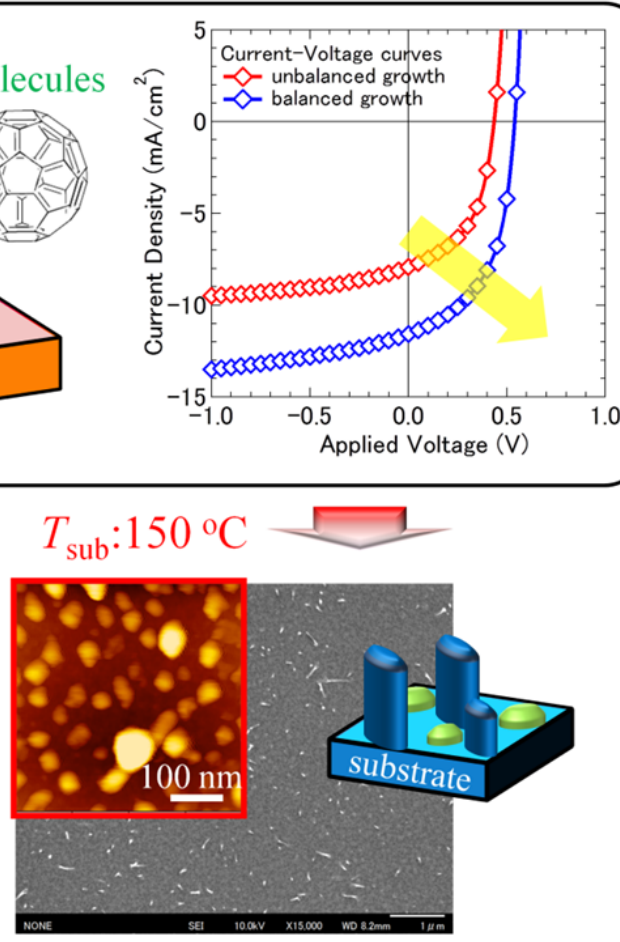

Unbalanced Growth 


\section{Introduction}

Vacuum-processed organic photovoltaics (OPVs) based on small molecules have been studied as a means of realizing tandem-structured OPVs to stack certain single cells $[1,2]$. The application of the bulk heterojunction (BHJ) structure, which is a mixture of electron donor and acceptor molecules, in high-performance single OPV has been investigated since the 1990s [3]. The exciton (photoexcited electron-hole binding pair) diffusion length in organic thin films is extremely short (limited to within several nanometers), and the presence of an interface area between the donor and acceptor contributes to exciton dissociation. The concept of BHJ structure is widely-distributed interface area in thin films. Therefore, the BHJ structure has the potential to yield enhanced photocurrent density. Co-evaporation method has been commonly used in order to fabricate OPV cells incorporating the BHJ structure. In this method, donor and acceptor molecules are sublimed by separate sources in vacuum [3]. The BHJ structures composed of metal-phthalocyanines and fullerene $\left(\mathrm{C}_{60}\right)$ have been reported, with materials being chosen on account of their high absorption coefficients and chemical stability, respectively. The metal phthalocyanines having high molecular planarity such as zinc-phthalocyanine $(\mathrm{ZnPc})$ establish high mobility and light absorption at the Q-band, because of the strong $\pi-\pi$ overlap [4]. Hence, OPV devices incorporated BHJ 
Y. Shibata et.al

structure composed of $\mathrm{ZnPc}$ and $\mathrm{C}_{60}$ exhibit a photocurrent density $\left(J_{\mathrm{sc}}\right)$ exceeding 10 $\mathrm{mA} / \mathrm{cm}^{2}[5-8]$.

Recently, it was reported that structural control of co-evaporated films leads to improved photovoltaic performance [9], for example, in case of phase-separated structures [10] and nano-sized crystal grains [11]. However, the growth process during the co-evaporation of film used in high-performance BHJ structures has not been explored; this is because of the difficulty in analyzing these structures. To date, the film morphology and crystallinity of BHJ films has been controlled by tuning the substrate temperature $\left(T_{\text {sub }}\right)$ only $[8,11,12]$. The quality of vacuum-evaporated films including the morphology and the crystal size depends on the rate of crystal nucleation, and $T_{\text {sub }}$ and deposition rate $\left(V_{\text {depo }}\right)$ during deposition are well-recognized as factors affecting the crystal size control [13]. Therefore, we may reasonably suppose that the crystallinity of the co-evaporation films can be controlled by varying $T_{\text {sub }}$ and $V_{\text {depo }}$ during co-evaporation in vacuum.

Here, we report on the relationship between OPV device performance and growth control of the $\mathrm{ZnPc}: \mathrm{C}_{60}$ blend films used in these devices. We also report on a structural analysis of the co-evaporated films, based on the initial donor and acceptor growth 
modes. We discuss the optimal growth process for the production of co-evaporated films suitable for high-performance OPVs.

\section{Experimental Details}

\subsection{Device fabrication}

The OPV devices were fabricated in a vacuum evaporation system at a pressure of $10^{-5}$

Pa. ZnPc (purity $97 \%$ ) and $\mathrm{C}_{60}$ (purity $99.9 \%$ ) were purchased from Sigma-Aldrich and Materials Technologies Research, Ltd., respectively. The organic materials were purified by repeated sublimation prior to evaporation. The OPV devices were fabricated as follows: (1) Indium-tin-oxide (ITO) -coated glass substrates (purchased from Sanyo Vacuum Industry Co., Ltd) were cleaned in oxygen plasma for $30 \mathrm{~min}$. The thickness and sheet resistance of the ITO films were $150 \mathrm{~nm}$ and less than $15 \Omega / \square$, respectively.

(2) A BHJ layer composed of $\mathrm{ZnPc}$ and $\mathrm{C}_{60}$ was simultaneously evaporated onto the ITO. The growth conditions of the $\mathrm{ZnPc}: \mathrm{C}_{60} \mathrm{BHJ}$ layer were controlled by tuning $T_{\text {sub }}$ and $V_{\text {depo }}$ during the evaporation process, within ranges of $30-150{ }^{\circ} \mathrm{C}$ and $0.02-0.08$

$\mathrm{nm} / \mathrm{s}$, respectively. Here, $V_{\text {depo }}$ was defined as $V_{\text {depo }} \equiv V_{\mathrm{ZnPc}}=V_{\mathrm{C} 60}$, where $V_{\mathrm{ZnPc}}$ and $V_{\mathrm{C} 60}$ are $\mathrm{ZnPc}$ and $\mathrm{C}_{60}$ deposition rate, respectively. Therefore, the volume ratio of the $\mathrm{ZnPc}: \mathrm{C}_{60} \mathrm{BHJ}$ films was fixed at $\mathrm{ZnPc}: \mathrm{C}_{60}=1: 1(\mathrm{v} / \mathrm{v} \%) . V_{\text {depo }}$ was monitored by two separate quartz crystal oscillators. (3) The substrate was cooled to room temperature. (4) 
Finally, $\mathrm{C}_{60}$ films (60-nm thickness), bathocuproine (BCP: 6-nm thickness), and aluminum (Al: $100 \mathrm{~nm}$ ), as an electron transport layer, exciton blocking layer [14], and an electrode, respectively, were evaporated sequentially. The OPV device configuration was ITO/ZnPc: $\mathrm{C}_{60}=1: 1 / \mathrm{C}_{60}(60 \mathrm{~nm}) / \mathrm{BCP}(6 \mathrm{~nm}) / \mathrm{Al}(80 \mathrm{~nm})$. To prevent morphological change of the electron blocking layer during substrate heating, we excluded typical poly(3,4-ethylenedioxythiophene) polystyrene sulfonate (PEDOT:PSS) and molybdenum oxide [15] from the device design. The device area was $0.04 \mathrm{~cm}^{2}$.

\subsection{Measurements}

The current-voltage $(J-V)$ characteristics were measured using a source meter (KEITHLEY 2400 series, Keithley Instruments Inc.), and the light source (air mass: 1.5G, light intensity: $100 \mathrm{~mW} / \mathrm{cm}^{2}$ ) used for the light irradiation test of the OPVs was calibrated with a silicon-photodiode (Bunko Keiki Co., Ltd). $J$ - $V$ curves of the OPV devices were measured in an $\mathrm{N}_{2}$ atmosphere without exposure to ambient air. Here, we calculated the series resistance $(R \mathrm{~s})$ and parallel resistance $\left(R_{\mathrm{p}}\right)$ from curve fitting of the dark current with the Shockley diode model, in accordance with references [16-18] and using.

$$
V=n \frac{k_{B} T}{q} \ln \left(\frac{J}{J_{0}}\right)
$$


where $V$ is the applied voltage, $k_{\mathrm{B}}$ is the Boltzmann constant, $T$ is the temperature, $q$ is the electronic charge, $n$ is the ideal factor, $J_{\mathrm{o}}$ the is reverse saturation current density, and $J$ is the current density.

The light absorption spectra of the $\mathrm{ZnPc}: \mathrm{C}_{60}$ films were measured using a SM-25K xenon lamp (Bunko Keiki Co.,Ltd) equipped with a monochrometer. The film morphology was observed using atomic force microscope (AFM; Nanonavi E-sweep: Seiko Instruments Inc.) with dynamic force mode and a scanning electron microscopy (SEM, JSM-6340F: JEOL Co., Ltd) with accelerate voltage of $10 \mathrm{kV}$. To observe the initial growth mode, molecules were deposited onto a cleaned silicon oxide $\left(\mathrm{SiO}_{2}\right)$ substrate. In initial growth stage, the monitored thickness by crystal quartz oscillators was 5-10 nm. The grazing incidence wide-angle X-ray scattering (GIWAXS) utilizing synchrotron irradiation was measured at beam line BL46XU (at the SPring-8 synchrotron radiation which was equipped with a two-dimensional counter, PILATUS 300K (DECTRIS Ltd.)). The X-ray wavelength and camera length were $1.2 \AA$ and $148.8 \mathrm{~mm}$, respectively. 


\section{Results and Discussion}

\subsection{Optical properties of growth-controlled ZnPc: $\mathrm{C}_{60}$ co-evaporated films}

Fig. 1 shows the ultraviolet(UV)/visible-light absorption spectra of the co-evaporated $\mathrm{ZnPc}: \mathrm{C}_{60}$ films. The $300-500-$ and $550-800-\mathrm{nm}$ absorbance corresponds to $\mathrm{C}_{60}$ and ZnPc, respectively. ZnPc also has absorption peak around 350-nm wavelength. Further, the absorption peaks at 550-800-nm wavelength are strongly dependent on the crystal phase of the ZnPc molecules, because of the polymorphic phase $[19,20]$. The $\alpha$-phase ZnPc crystalline films have two absorption peaks at 620- and 696-nm wavelength [21]. It is apparent that co-evaporated $\mathrm{ZnPc}: \mathrm{C}_{60}$ films having $\alpha$-phase $\mathrm{ZnPc}$ crystals were obtained regardless of the growth condition, as shown in Fig. 1 (a-b). In contrast, it was reported that the crystal structures of the single-component $\mathrm{ZnPc}$ films are strongly dependent on $T_{\text {sub }}$ and $V_{\text {depo }}[13]$. Therefore, these results indicate that the crystal growth of co-evaporated films is limited, owing to the competitive growth between the donors and acceptors during the co-evaporation process. 


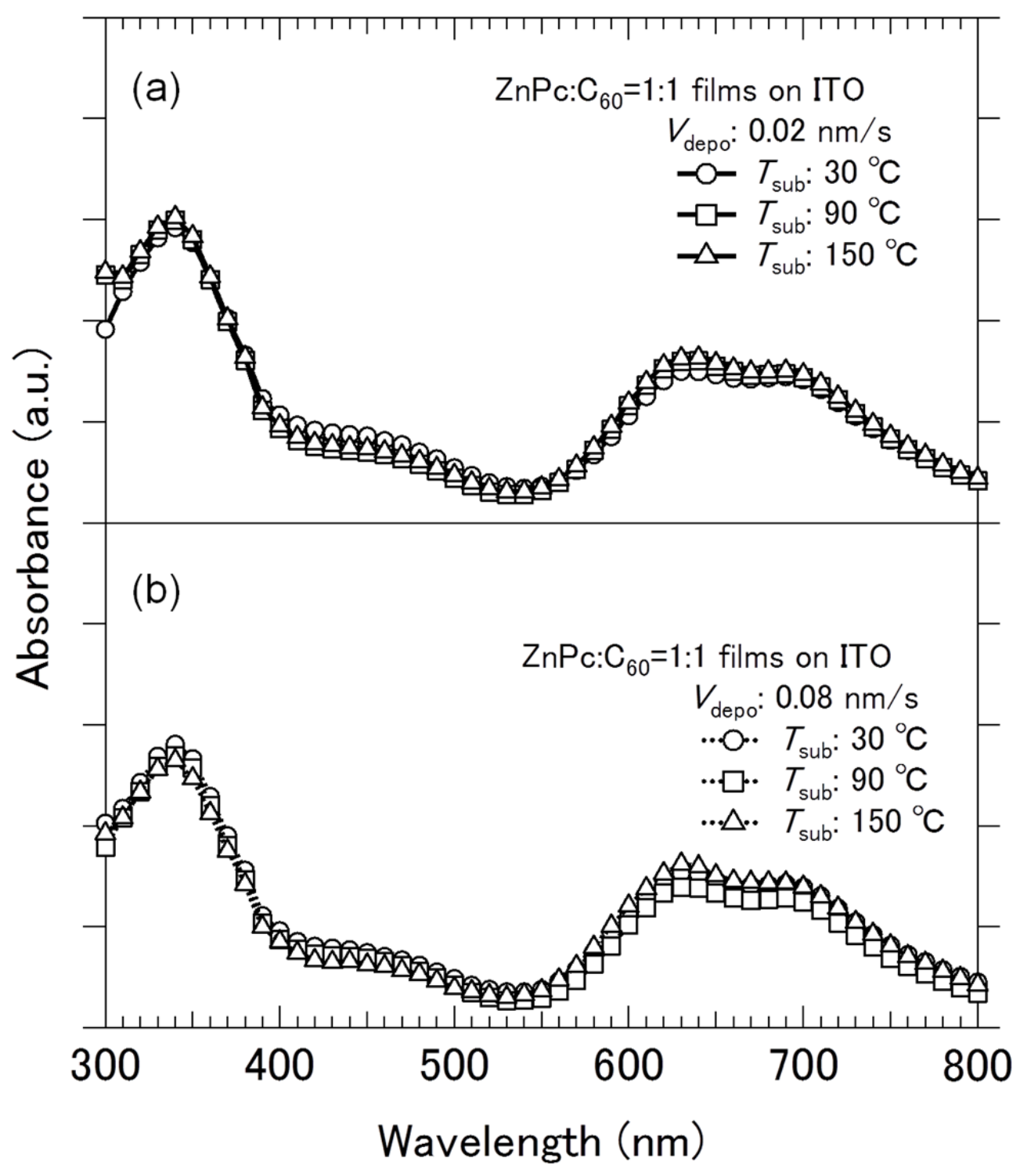

Fig.1. Ultraviolet(UV)/visible light absorption spectra of co-evaporated $\mathrm{ZnPc}: \mathrm{C}_{60}$ films (20-nm thickness) on glass/ITO substrate. (a) Deposition rate $\left(V_{\text {depo }}\right): 0.02 \mathrm{~nm} / \mathrm{s}$ (b) $V_{\text {depo: }}: 0.08 \mathrm{~nm} / \mathrm{s}$. 
Y. Shibata et.al

\subsection{Surface morphology of ZnPc: $\mathrm{C}_{60}$ co-evaporated films}

Fig. 2 shows AFM images of the co-evaporated $\mathrm{ZnPc} \mathrm{C}_{60}$ film surfaces and their root-mean-square (RMS) roughness values. The surface morphologies of these $\mathrm{ZnPc}: \mathrm{C}_{60}$ films were dependent on both $T_{\text {sub }}$ and $V_{\text {depo }}$, under different condition. When $T_{\text {sub }}$ was increased from $30{ }^{\circ} \mathrm{C}$ to $90{ }^{\circ} \mathrm{C}$, a relatively smooth surface and nano-sized grains were obtained, regardless of $V_{\text {depo, }}$, as shown in Fig.2 (a, b, d, e). The ZnPc: $\mathrm{C}_{60}$ film surfaces became extremely rough at a $T_{\text {sub }}$ of $150{ }^{\circ} \mathrm{C}$, as shown in Fig. 2 (c, f). The corresponding increase in the RMS values can be attributed to molecular-aggregation structures, such as islands, protruding in the out-of-plane direction from the ITO substrate. Compared with slow $V_{\text {depo }}(0.02 \mathrm{~nm} / \mathrm{s})$, fast $V_{\text {depo }}(0.08 \mathrm{~nm} / \mathrm{s})$ condition led to the formation of numerous island structures. The calculated number densities of the island-like structures shown in Fig. 2 (c) and (f) were 14.5 and $61.5 \mu \mathrm{m}^{-2}$, respectively. The heights of these structures, which were evaluated from the contrast bars in AFM images, were ca. 30-45 $\mathrm{nm}$. Thus, the surface roughness of the $\mathrm{ZnPc}: \mathrm{C}_{60} \mathrm{BHJ}$ films was dramatically increased by increases in $T_{\text {sub }}$ rather than by adjustment of $V_{\text {depo }}$. In order to investigate the surface morphologies of $\mathrm{ZnPc}_{\mathrm{C}} \mathrm{C}_{60} \mathrm{BHJ}$ films in more detail, we examined the large-scale AFM topography images, such as those shown in Fig. 2 (e, f). It was confirmed that the grain size at a $T_{\text {sub }}$ of $150{ }^{\circ} \mathrm{C}$ was larger than that at $90^{\circ} \mathrm{C}$. 
Y. Shibata et.al

With a view to analyzing the $\mathrm{ZnPc}$ and $\mathrm{C}_{60}$ distributions in the aggregation structures protruding perpendicular to the ITO substrate, we examined the phase images of the large-scale AFM images, as shown in Fig. 2 (i, j). In principle, a phase indicates the presence of distinct materials. However, in this case, it is difficult to distinguish the $\mathrm{ZnPc}$ from $\mathrm{C}_{60}$ because there is no obvious difference in contrast. Then, we focused on the individual growth modes of the $\mathrm{ZnPc}$ and $\mathrm{C}_{60}$ molecules, because organic molecules have specific crystal habits. 

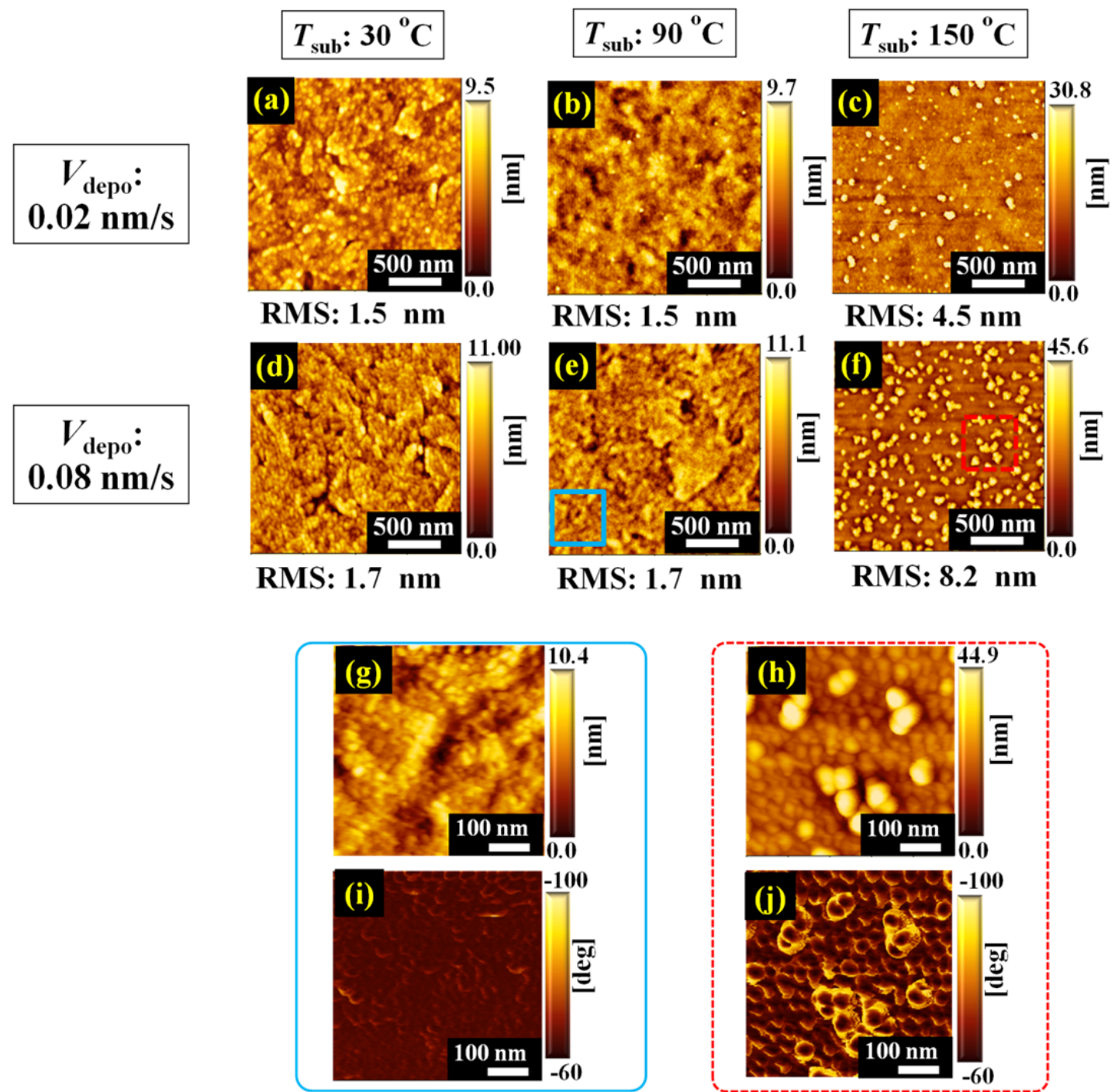

Fig.2. Atomic force microscopy images of co-evaporated $\mathrm{ZnPc}: \mathrm{C}_{60}=1: 1 \mathrm{v} / \mathrm{v} \%(20-\mathrm{nm}$ thickness) film surface onto ITO substrate and root-mean-square (RMS) roughness values. $(a-f)$ Topography images. (g, h) Large-scale topography images. (i, j) Phase images of large-scaled images. $T_{\text {sub }}$ : substrate temperature, $V_{\text {depo }}$ : deposition rate. 
Y. Shibata et.al

\subsection{Effects of substrate temperature on initial growth mode}

Fig. $3(a-d)$ shows AFM images of the initial growth stages of single-component $\mathrm{ZnPc}$ and $\mathrm{C}_{60}$ molecules. In the single-component $\mathrm{C}_{60}$ growth shown in Fig. 3 (a) and (b), a large number of grains can be observed. It can also be seen that the sizes of the grains composed of $\mathrm{C}_{60}$ molecules increase with increasing $T_{\text {sub}}$, while the crystal nucleation rate decreases. A ca. 1.8-fold height increase, which evaluated from the contrast bar, was obtained from these figures. Note that the $\mathrm{C}_{60}$ molecules tended strongly towards three-dimensional aggregation with increasing $T_{\text {sub }}$, whereas the evaporated $\mathrm{C}_{60}$ molecules exhibited the Volmer-Weber growth mode. On the other hand, a ca.8-fold height increase (as evaluated from the contrast bar) obtained for $T_{\text {sub }}$ values $90{ }^{\circ} \mathrm{C}-150{ }^{\circ} \mathrm{C}$ for the single-component ZnPc molecules, as shown in Fig. 3 (c, d). A relatively smooth surface was obtained at a $T_{\text {sub }}$ of $90{ }^{\circ} \mathrm{C}$ for this substance. This indicates that $\mathrm{ZnPc}$ has strong molecular interaction in the $\pi$ - $\pi$ stacking direction, similar to the Stranski-Krastanov growth mode. When $T_{\text {sub }}$ was increased to $150{ }^{\circ} \mathrm{C}$, the ZnPc molecules preferentially protruded outward from the ITO substrate. Senthilarasu et.al has reported that needle-like or one-dimensional crystal growth of ZnPc occurred at $150{ }^{\circ} \mathrm{C}[21,22]$. This difference in growth mode can be attributed to the the $\mathrm{ZnPc}$ molecules crystal phase. 


\section{Y. Shibata et.al}

From the above results, we found that the crystal growth modes of the $\mathrm{C}_{60}$ and $\mathrm{ZnPc}$ molecules differed. Considering these results, we also observed the initial growth modes of the co-evaporated $\mathrm{ZnPc}: \mathrm{C}_{60}$, as shown in Fig. 3 (e, f). At a $T_{\text {sub }}$ of $90{ }^{\circ} \mathrm{C}$, a blend morphology composed of plate-like and island-like crystallites was observed. The maximum bar height increased with $T_{\text {sub }}$. Interestingly, the maximum height in the contrast bar of single-component $\mathrm{ZnPc}$ at a $T_{\text {sub }}$ of $150{ }^{\circ} \mathrm{C}$ was consistent with that of the co-evaporated $\mathrm{ZnPc}: \mathrm{C}_{60}$ blend at the same $T_{\text {sub }} 150{ }^{\circ} \mathrm{C}$. Therefore, there is a possibility that the enhancement of the surface roughness observed in the co-evaporated $\mathrm{ZnPc}: \mathrm{C}_{60}$ films at a $T_{\text {sub }}$ of $150{ }^{\circ} \mathrm{C}$ (Fig. 2 (f)) can be attributed to the one-dimensional growth trend of the $\mathrm{ZnPc}$ crystals on the substrates.

We also show SEM images of the initial growth stages of the $\mathrm{ZnPc}: \mathrm{C}_{60}$ blend at $T_{\text {sub }}$ values of 90 and $150{ }^{\circ} \mathrm{C}$ in Fig. 3 (g, h). Here, monitored thickness was increased up to $10 \mathrm{~nm}$ in order to track the crystal growth in co-evaporated films. In the case of a $T_{\text {sub }}$ of $90{ }^{\circ} \mathrm{C}$, homogeneous growth and a smooth surface were obtained. This indicates that balanced film growth occurred between the $\mathrm{C}_{60}$ and $\mathrm{ZnPc}$. In contrast, at a $T_{\text {sub }}=150{ }^{\circ} \mathrm{C}$, the surface morphology exhibited not only three-dimensional grains near the substrate surface, but also a needle-like structure elsewhere in the sample. The $\mathrm{C}_{60}$ molecules cannot show the one-dimensional or needle-like growth mode in thin films because 


\section{Y. Shibata et.al}

fullerene molecules have three-dimensional molecular interaction due to spherical molecule [23]. From the cross-sectional SEM image in Fig. 3 (i), it is clear that the needle-like structure particularly contributes to the enhanced surface roughness. Therefore, these SEM images also support the crystal growth mechanism suggested above.

Compared with the initial growth stage of the co-evaporated films at a $T_{\text {sub }}$ of $150{ }^{\circ} \mathrm{C}$, we found that balanced film growth between the $\mathrm{C}_{60}$ and $\mathrm{ZnPc}$ occurred during the co-evaporation process conducted at a $T_{\text {sub }}$ of $90{ }^{\circ} \mathrm{C}$. 


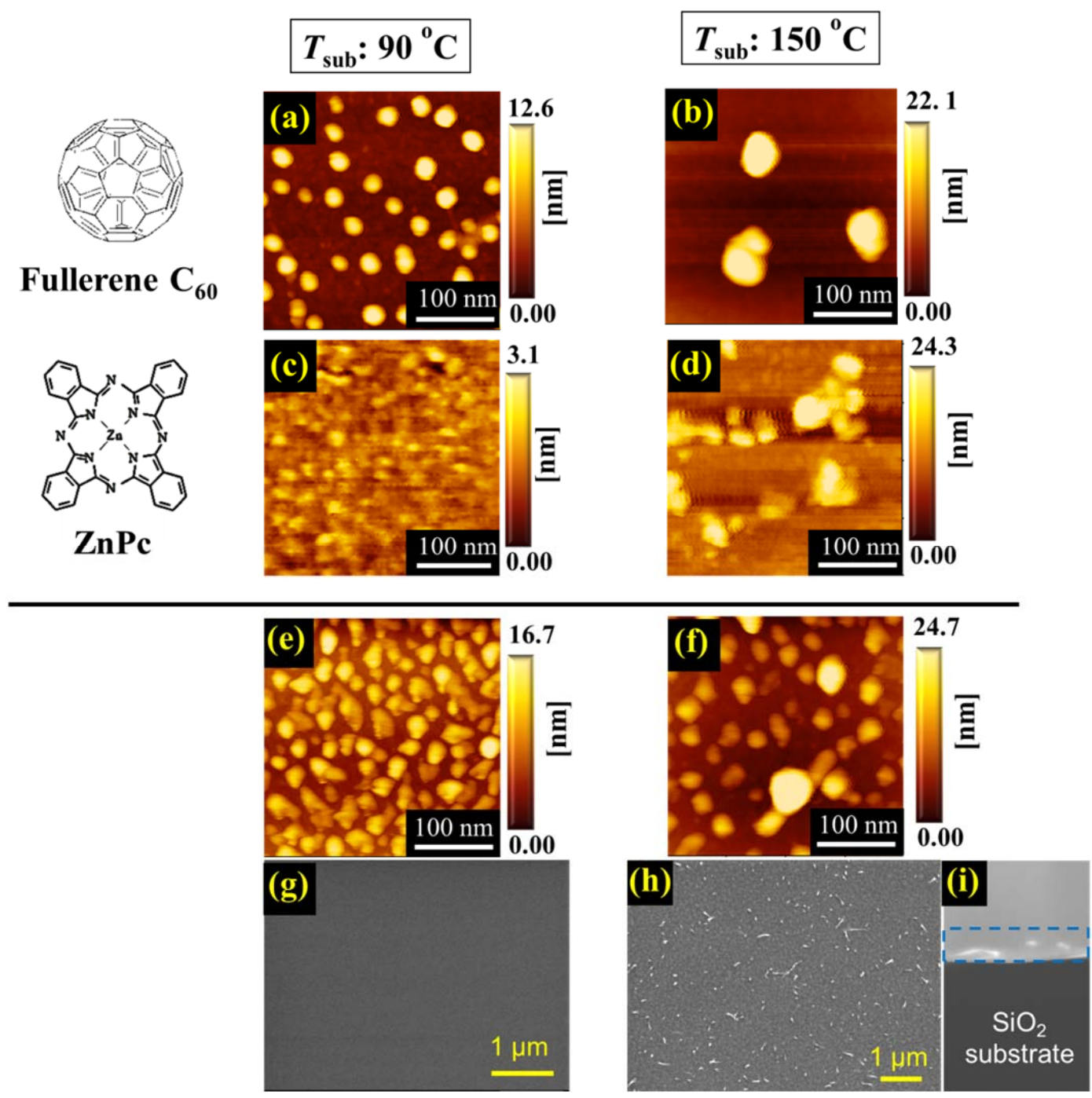

Fig. 3. Atomic force microscopy (AFM) images of initial growth stages (5-nm thickness, $\left.V_{\text {depo }}=0.02 \mathrm{~nm} / \mathrm{s}\right)$ and molecular structures of: $(\mathrm{a}, \mathrm{b})$ Single-component $\mathrm{C}_{60}$, (c, d) single-component $\mathrm{ZnPc}$, and (e, f) co-evaporated $\mathrm{ZnPc}_{\mathrm{C}} \mathrm{C}_{60}=1: 1$. (g, h) In-plane scanning electron microscopy (SEM) images of co-evaporated $\mathrm{ZnPc}_{\mathrm{C}} \mathrm{C}_{60}$ at $10-\mathrm{nm}$ thickness, $V_{\text {depo }}=0.02 \mathrm{~nm} / \mathrm{s}$. (i) Cross-sectional SEM images of (h). 


\subsection{Photovoltaic device}

In order to understand the suitable BHJ structure for high-performance, the relationship between the growth-controlled BHJ structures and the photovoltaic performance of devices incorporating these films which was incorporated these films is of importance. Fig.4 (a) and Table 1 show the $J-V$ characteristics of devices produced at $T_{\text {sub }}$ values of 90 and $150{ }^{\circ} \mathrm{C}$ under light irradiation and extracted photovoltaic parameters, respectively. The power conversion efficiency (PCE) of the co-evaporated $\mathrm{ZnPc}: \mathrm{C}_{60}$ films at a $T_{\text {sub }}$ of $90{ }^{\circ} \mathrm{C}$ is higher than that at a $T_{\text {sub }}$ of $150{ }^{\circ} \mathrm{C}$. In particular, the open-circuit voltage $\left(V_{\text {oc }}\right)$ and fill factor decreased at a $T_{\text {sub }}$ of $150{ }^{\circ} \mathrm{C}$. In addition, we calculated the series resistance $\left(R_{\mathrm{S}}\right)$ and parallel resistance $\left(R_{\mathrm{p}}\right)$ of devices produced at

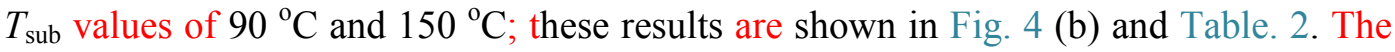
calculated $R_{\mathrm{S}}$ values are approximately identical regardless of growth condition. This indicates that carrier transport network is fully established in BHJ films. On the other hand, a difference was observed in the $R_{\mathrm{p}}$ values, which indicate current leakage in the devices. It is well known that the optimal $V_{\mathrm{oc}}$ is determined by difference between the lowest unoccupied molecular orbital (LUMO) level of acceptor and the highest occupied molecular orbital (HOMO) level of donor $[24,25]$. For the $\mathrm{ZnPc}$ and $\mathrm{C}_{60}$ combination, the optimal $V_{\mathrm{oc}}$ was calculated ca. $0.6 \mathrm{~V}$ [26]. $V_{\mathrm{oc}}$ loss in OPV devices is 
conventionally explained by the Langevin recombination model $[27,28]$, where reductions of the optimal $V_{\text {oc }}$ are determined by the exciton generation rate and the dissociation probability of the electron-hole pairs into free carriers. To obtain efficient exciton dissociation, a broad donor-acceptor interface area and large exiciton diffusion length are required. Thus, it is that the unbalanced film growth shown in Fig. 3 (f, h) leads to a morphologically narrow donor-acceptor interface area because of the low $J_{\mathrm{sc}}$. For further improvement of device performance, we optimized the co-evaporated film thickness. The maximum PCE of ca. 3.0 \% was obtained at 50-nm thickness without electron blocking layer, as can be seen in Table 1. As the thickness increased slightly, $J_{\text {sc }}$ increased dramatically, up to $11 \mathrm{~mA} / \mathrm{cm}^{2}$. This is attributed to the greater light absorption capacity of BHJ devices.

Fig. 4 (c) shows a GIWAXS image of a co-evaporated ZnPc: $\mathrm{C}_{60}$ film (50-nm thickness, $T_{\text {sub }}=90{ }^{\circ} \mathrm{C}$ and $V_{\text {depo }}=0.02 \mathrm{~nm} / \mathrm{s}$ ) on ITO/glass substrate. In the GIWAXS image, a diffraction ring pattern appears at approximately scattering vector $q_{\mathrm{Z}}=0.49 \AA^{-1}$, and the calculated $d$-spacing value was ca. $13 \AA$. This is attributed to randomly-oriented $\alpha$-pahse ZnPc crystals, as evidenced by Fig. 1. The $\mathrm{C}_{60}$ molecules exhibit amorphous configuration, as indicated by the non-diffraction pattern. In the co-evaporation process, the $\mathrm{C}_{60}$ crystal growth was limited despite the growth control, and the co-evaporated 
Y. Shibata et.al

$\mathrm{ZnPc}: \mathrm{C}_{60}$ films with PCE ca. 3\% were constructed using with $\mathrm{ZnPc}$ nano-sized crystal and amorphous $\mathrm{C}_{60}$, shown in illustrated Fig. 4 (d). Balanced crystal growth between the donors and acceptors is one of important factors in the fabrication of a BHJ structure using a vacuum process. 

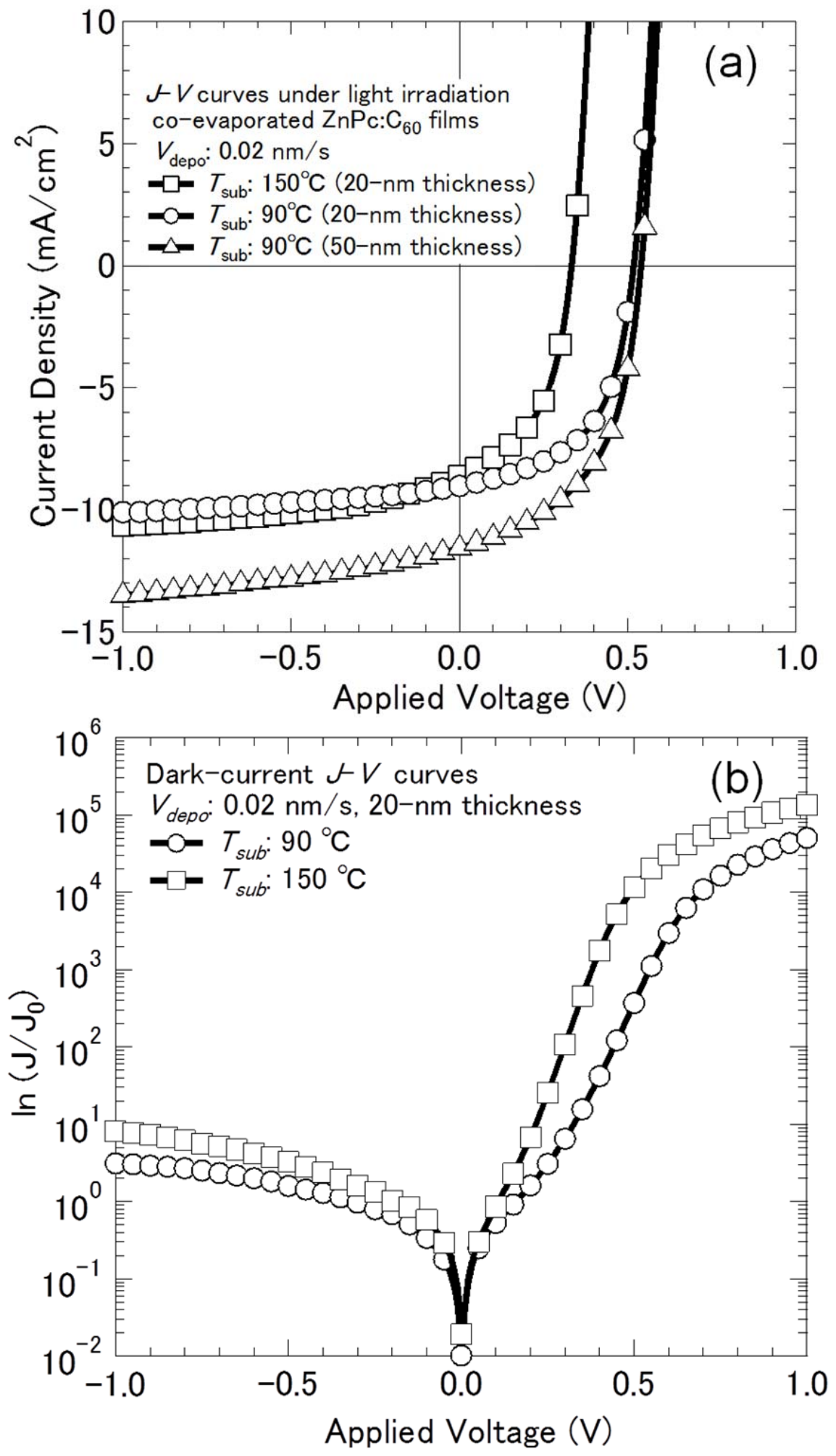

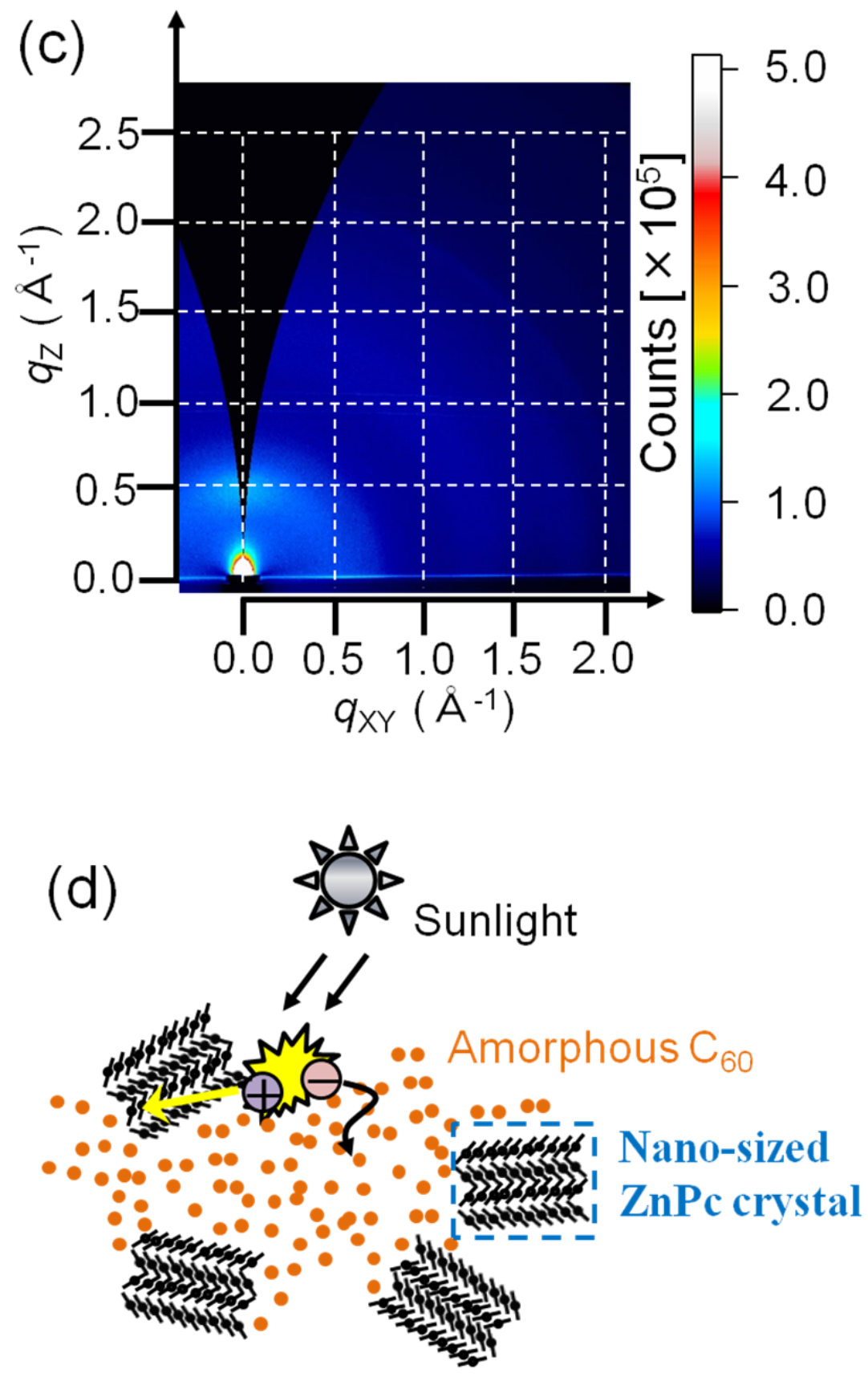

Fig. 4. (a) Current-voltage $(J-V)$ characteristics under light irradiation with air mass $1.5 \mathrm{G}$, intensity of $100 \mathrm{~mW} / \mathrm{cm}^{2}$. (b) Semilogarithmic $J-V$ plots in dark. (c) Grazing incidence wide-angle X-ray scattering image of glass/ITO/ZnPc: $\mathrm{C}_{60}$ (50-nm thickness), substrate temperature $\left(T_{\text {sub }}\right): 90{ }^{\circ} \mathrm{C}$, deposition rate $\left.\left(V_{\text {depo }}\right): 0.02 \mathrm{~nm} / \mathrm{s}\right)$. (d) Illustration of high-performance $\mathrm{ZnPc}: \mathrm{C}_{60}$ co-evaporated film structure. 
Table 1. Photovoltaic parameters extracted from light $J-V$ curves.

\begin{tabular}{ccccc}
\hline Device & $J_{\mathrm{sc}}\left(\mathrm{mA} / \mathrm{cm}^{2}\right)$ & $V_{\text {oc }}(\mathrm{V})$ & Fill Factor & PCE $(\%)$ \\
\hline $\begin{array}{c}T_{\text {sub }} 90{ }^{\circ} \mathrm{C} \\
(20 \text {-nm thickness })\end{array}$ & $8.93 \pm 0.14$ & $0.51 \pm 0.01$ & $0.54 \pm 0.01$ & $2.46 \pm 0.14$ \\
$T_{\text {sub }} 150{ }^{\circ} \mathrm{C}$ & $8.31 \pm 0.23$ & $0.30 \pm 0.03$ & $0.48 \pm 0.01$ & $1.20 \pm 0.19$ \\
$(20$-nm thickness $)$ & & & & \\
$T_{\text {sub }} 90{ }^{\circ} \mathrm{C}$ & $11.69 \pm 0.24$ & $0.53 \pm 0.01$ & $0.47 \pm 0.01$ & $2.91 \pm 0.11$ \\
$(50$-nm thickness $)$ & & & & \\
\hline
\end{tabular}

Table 2. Diode parameters extracted from dark $J-V$ curves.

\begin{tabular}{ccccc}
\hline Device & $J_{\mathrm{o}}\left(\mu \mathrm{A} / \mathrm{cm}^{2}\right)$ & $n$ & $R_{\mathrm{s}}\left(\Omega \mathrm{cm}^{2}\right)$ & $R_{\mathrm{p}}\left(\mathrm{k} \Omega \mathrm{cm}^{2}\right)$ \\
\hline $\begin{array}{c}T_{\text {sub }} 90^{\circ} \mathrm{C} \\
(20-\mathrm{nm} \text { thickness }) \\
\begin{array}{c}T_{\text {sub }} 150^{\circ} \mathrm{C} \\
(20-\mathrm{nm} \text { thickness })\end{array}\end{array}$ & 5.1 & 1.1 & 0.2 & 3.28 \\
\hline
\end{tabular}




\section{Conclusion}

In summary, we investigated the relationship between the surface morphologies of growth-controlled $\mathrm{ZnPc}: \mathrm{C}_{60}=1: 1$ bulk heterojunction films and the performance of organic photovoltaic devices incorporating these films. It was found that the surface morphology of the co-evaporated $\mathrm{ZnPc}: \mathrm{C}_{60}$ samples was affected both the substrate temperature and the deposition rate. Further, the crystal growth of co-evaporated $\mathrm{ZnPc}: \mathrm{C}_{60}$ films was limited during the evaporation process. We also conducted morphological analysis of the co-evaporated thin films, focusing initial growth modes.

We suggest that balanced film growth between donor and acceptor molecules during the evaporation process results in high-performance BHJ structures suitable for use in organic photovoltaics.

\section{Acknowledgements}

This work was supported by the Core Research for Evolutional Science and Technology (CREST) of the Japan Science and Technology Agency (JST). The synchrotron GIWAXS measurements were conducted at SPring-8 (BL46XU beam line, Japan) with the approval of the Japan Synchrotron Radiation Research Institute (JASRI; Nos. 2013A1629 and 2013A1781). We thank Dr. Tomoyuki Koganezawa (JASRI) for advice on the GIWAXS measurement. The SEM measurements were supported by Ms. Yuka Yoshinuma and Dr. Masashi Kuwahara (National Institute of Advanced Industrial Science and Technology (AIST)). 


\section{Y. Shibata et.al}

\section{References}

[1] X. Che, X. Xiao, J.D. Zimmerman, D. Fan, S.R. Forrest, High-efficiency, vacuum-deposited, small-molecule organic tandem and triple-junction photovoltaic cells, Adv. Energy Mater. 4 (2014) 1400568.

[2] J.D. Zimmerman, B.E. Lassiter, X. Xiao, K. Sun, A. Dolocan, R. Gearba, D.A. Vandenbout, K.J. Stevenson, P. Wickramasinghe, M.E. Thompson, S.R. Forrest, Control of interface order by inverse quasi-epitaxial growth of squaraine/fullerene thin film photovoltaics, ACS Nano. 7 (2013) 9268-9275.

[3] M. Hiramoto, H. Fujiwara, M. Yokoyama, Three-layered organic solar cell with a photoactive interlayer of codeposited pigments, Appl. Phys. Lett. 58 (1991) $1062-1064$.

[4] S. Senthilarasu, R. Sathyamoorthy, S. Lalitha, A. Sabbarayan, K. Natarajan, Thermally evaporated ZnPc thin films-Band gap dependence on thickness, Sol. Energy Mater. Sol. Cells 82 (2004) 179-186.

[5] W. Zheng, K.S. Yong, Z.M. Kam, F. Zhu, Y. Li, Effect of blend layer morphology on performance of $\mathrm{ZnPc:} \mathrm{C}_{60}$-based photovoltaic cells, Appl. Phys. Lett. 97 (2010) 133304.

[6] B. Yu, L. Huang, H. Wang, D. Yan, Efficient organic solar cells using a high-quality crystalline thin film as a donor layer, Adv. Mater. 22 (2010) 1017-1020.

[7] K. Iketaki, T. Kaji, S. Nakao, M. Hiramoto, Structural studies of the codeposited i -layer of ZnPc:C60 p-i-n solar cells Phys. Status. Solidi C, 8 (2011) 637-639.

[8] S. Pfuetzner, J. Meiss, A. Petrich, M. Riede, K. Reo, Thick $\mathrm{C}_{60}: Z_{n}$ Pc bulk heterojunction solar cells with improved performance by film deposition on heated substrates, Appl. Phys. Lett. 94 (2012) 253303. 


\section{Y. Shibata et.al}

[9] Y. Shibata, T. Kono, N. Komura, Y. Yoshida, Structural control of bulk heterojunction films based on oligothiophene with sterically-bulky groups, Org. Electron. 14 (2013) 1073-1080.

[10] Z. Wang, T. Miyadera, T. Yamanari, Y. Yoshida, Templating effects in molecular growth of blended films for efficient small-molecule photovoltaics, ACS Appl. Mater. Interfaces. 6 (2014) 6369-6377.

[11] S. Pfuetzner, J. Meiss, A. Petrich, M. Riede, K. Reo, The influence of substrate heating on morphology and layer growth in $\mathrm{C}_{60}: \mathrm{ZnPc}$ bulk heterojunction solar cells, Org. Electron. 12 (2011) 435-441.

[12] K.-C. Chiu, L.-T. Juey, C.-F. Su, S.-J. Tang, M.-N. Jong, S.-S. Wang, J.-S. Wang, C.-S. Yang, W.-C. Chou, Effects of source and substrate temperatures on the properties of ITO $/ \mathrm{CuPc} / \mathrm{C}_{60}$ heterostructure prepared by physical vapor deposition, J. Cryst. Growth. 310 (2008) 1734-1738.

[13] F. Yang, M. Shtein, S.R. Forrest, Morphology control and material mixing by high-temperature organic vapor-phase deposition and its application to thin-film solar cells J. Appl. Phys. 98 (2005) 014906.

[14] H. Gommans, B. Verreet, B.P. Rand, R. Muller, J. Poortmans, P. Heremans, J. Genoe, On the role of bathocuproine in organic photovoltaic cells, Adv. Funct. Mater. 18 (2008) 3686.

[15] J. Jung, D. Kim, W.S. Shin, S.-J. Moon, C. Lee, S.C. Yoon, Highly efficient organic photovoltaic cells with molybdenum oxide buffer layer, Jpn. J. Appl. Phys. 49 (2010) 05EB05. 


\section{Y. Shibata et.al}

[16] S. Yoo, B. Domercq, B. Kippelen, Intensity-dependent equivalent circuit parameters of organic solar cells based on pentacene and $\mathrm{C}_{60}$, J. Appl. Phys. 97 (2005) 103706.

[17] W. J. Potscavage Jr., A. Sharma, B. Kippelen, Critical interfaces in organic solar cells and their influence on the open-circuit voltage, ACS. Chem. Res. 42 (2009) $1758-1767$.

[18] T. Kim, H. Shim, M. Choi, H. Kim, J. Kim, Multilayer epitaxial growth of lead phthalocyanine and $\mathrm{C}_{70}$ using $\mathrm{CuBr}$ as a templating layer for enhancing the efficiency of organic photovoltaic cells, ACS Appl. Mater. Interfaces, 6 (2014) $4286-4291$.

[19] M. Szybowicz, W. Bała, K. Fabisiak, K. Paprocki, M. Drozdowski, The molecular structure ordering and orientation of the metallophthalocyanine $\mathrm{CoPc}, \mathrm{ZnPc}, \mathrm{CuPc}$, and $\mathrm{MgPc}$ thin layers deposited on silicon substrate, as studied by micro-Raman spectroscopy, J. Mater. Sci. 46 (2011) 6589-6595.

[20] M. Hiramoto, K. Kitada, K. Iketaki, T. Kaji, Near infrared light driven organic p-i-n solar cells incorporating phthalocyanine J-aggregate, Appl. Phys. Lett. 98 (2011) 023302.

[21] S. Senthilarasu, R. Sathyamoorthy, S.K. Kulkarni, Substrate temperature effects on structural orientations and optical properties of zincpthalocyanine $(\mathrm{ZnPc})$ thin films, Mater. Sci. Eng. B. 122 (2005) 100-105.

[22] S. Senthilarasu, Y.B. Hahn, S.-H. Lee, Structural analysis of zinc phthalocyanine (ZnPc) thin films: X-ray diffraction study, J. Appl. Phys. 102 (2007) 043512.

[23] Thomas D. Anthopoulos, B. Singh, N. Marjanovic, N. S. Sariciftci, Alberto M. Ramil, H. Sitter, M. Cölle, Dago M. de Leeuw, High performance n-channel 


\section{Y. Shibata et.al}

organic field-effect transistors and ring oscillators based on $\mathrm{C}_{60}$ fullerene films, Appl. Phys. Lett. 89 (2006) 213504.

[24] T. Yamanari, T. Taima, J. Sakai, K. Saito, Origin of the open-circuit voltage of organic thin-film solar cells based on conjugated polymers, Sol. Energy Mater. Sol. Cells 93 (2009) 759-761.

[25] M.C. Scharber, D. Muhlbacher, M. Koppe, P. Denk, C. Waldauf, A.J. Heeger, C.J. Brabec, Design rules for donors in bulk-heterojunction solar cells-Towards $10 \%$ energy-conversion efficiency, Adv. Mater. 18 (2006) 789-794.

[26] R. Pode, On the problem of open circuit voltage in metal phthalocyanine $/ \mathrm{C}_{60}$ organic solar cells Adv. Mat. Lett. 2 (2011) 3-11.

[27] F. Zhang, F. Sun, Y. Shi, Z. Zhuo, L. Lu, D. Zhao, Z. Xu, Y. Wang, Effect of an ultra-thin molybdenum trioxide layer and illumination intensity on the performance of organic photovoltaic devices, Energy Fuels 24 (2010) 3739-3742.

[28] L.J.A. Koster, V.D. Mihailetchi, R. Ramaker, P.W.M. Blom, Light intensity dependence of open-circuit voltage of polymer:fullerene solar cells, Appl. Phys. Lett. 86 (2005) 123509. 